\title{
A Physical Map around the WAGR Complex on the Short Arm of Chromosome 11
}

\author{
M. Gessler ANd G. A. P. Bruns \\ Genetics Division, Children's Hospital and Department of Pediatrics, Harvard Medical School, Boston, Massachusetts 02115 \\ Received December 9, 1988; revised February 9. 1989
}

\begin{abstract}
A long-range restriction map of part of the short arm of chromosome 11 including the WAGR region has been constructed using pulsed-field gel electrophoresis and a number of infrequently cutting restriction enzymes. A total of $15.4 \mathrm{Mbp}$ has been mapped in detail, extending from proximal $11 \mathrm{p} 14$ to the distal part of 11p12. The map localizes 35 different DNA probes and reveals at least nine areas with features characteristic of HTT islands, some of which may be candidates for the different loci underlying the phenotype of the WAGR syndrome. This map will furthermore allow screening of DNA from individuals with WAGR-related phenotypes and from Wilms tumors for associated chromosomal rearrangements. - 1889 Acndomic Prem, Ine.
\end{abstract}

\section{INTRODUCTION}

The WAGR syndrome, composed of Wilms tumor, aniridia, genitourinary abnormalities, and mental retardation, is frequently associated with deletions of the short arm of chromosome 11 including band p13 (Francke et al., 1979; Riccardi et al., 1980; Shannon et al., 1982; Turleau et ah, 1984). Deletions of functional alleles of the Wilms tumor gene or unmasking of a recessive mutant allele is proposed to result in the formation of Wilms tumor, a childhood nephroblastoma (Knudson and Strong, 1972; Fearon et al., 1984; Koufos et al., 1984; Orkin et al., 1984; Reeve et al., 1984). The large hemizygous deletions found in constitutional DNA of WAGR patients are thought to eliminate additional genes, giving rise to the developmental anomalies of the syndrome affecting the eye, the genitourinary tract, and the brain. These different features may also arise independently through localized mutational events, leading to singular symptoms like aniridia or perhaps genitourinary malformations (Simola et al., 1983; Moore et al., 1986; Porteous et al., 1987). Most Wilms tumors also occur without concomitant WAGR stigmata (Breslow and Beckwith, 1982), consistent with the hypothesis that several independent genes are located in the WAGR region on chromosome $11 \mathrm{p} 13$. The analysis of different WAGR-related deletions and translocations with probes for catalase and the $\beta$-subunit of follicle-stimulating hormone has regionalized the WAGR complex between these two genes in an area estimated at several million base pairs in size (Glaser et al., 1986; Porteous et al., 1987).

To characterize this region molecularly, we and other groups have characterized a large number of DNA probes from various chromosome 11-enriched libraries that map to different WAGR deletions (Bruns et al., 1987; Porteous et al., 1987; Davis et al., 1988; Lewis et al., 1988). Through the use of 30 probes together with 6 reference loci, a deletion map of the WAGR region has been established from analysis of 13 partially overlapping deletions which define 16 intervals, several of which could be correlated with phenotypic features (Gessler et al., 1989). New deletions can be mapped more precisely with this ordered bank of probes and the identification of rearrangements or very small deletions in subregions may lead to the genes underlying particular phenotypic features of the WAGR syndrome. Mapping of deletions on conventional Southern blots, however, cannot reveal translocations or microdeletions located between probes that do not affect the probe segments themselves.

Physical mapping of large chromosomal regions is now possible by pulsed-field gel electrophoresis (PFGE), which can separate DNA molecules up to several million base pairs in size (Schwartz and Cantor, 1984; Carle and Olsen, 1984). Restriction enzymes with $\mathrm{CpG}$ dinucleotides in their recognition sequence cut infrequently in mammalian DNA and produce fragments in this size range. These enzymes are sensitive to methylation and many of their sites are clustered in hypomethylated HTF islands (Brown and Bird, 1986). Furthermore, these islands are frequently associated with expressed sequences, making them prominent landmarks for a certain class of human genes (Bird, 1986; Lindsay and Bird, 1987). The application of long-range restriction mapping techniques has proven very useful in the molecular analysis of Duchenne muscular dystrophy and cystic fibrosis (Burmeister and Lehrach, 1986; Burmeister et al., 1988; Kenwrick et al., 1987; van Ommen et al., 1986; Drumm et al., 1988; Poustka et al., 1988).

Our probe bank for the WAGR deletion region has 
already been ordered in a highly resolving deletion map (Gessler et al, 1989). To anchor the probes in a detailed physical map and to create a framework for targeting individual loci associated with specific features of the WAGR syndrome, we developed a long-range restriction map that links all probes into three large clusters spanning more than $15 \mathrm{Mbp}$ and reveals a number of potential HTF islands.

\section{MATERIALS AND METHODS}

\section{Cell Lines and DNA Probes}

The lymphoblastoid cell line 6697 , derived from a karyotypically normal male, has been used to establish the map. For particular subregions additional cell lines were used. GM3809, GM5297, GM4613, and GM7427 were obtained from the NIGMS Human Genetic Mutant Cell Repository (Camden, NJ). H.V., a lymphoblastoid cell line from an individual with familial aniridia and the translocation $t(4 ; 11)(q 22 ; p 13)$, was provided by Dr. K. Simola (Simola et al., 1983). After informed consent, peripheral blood leukocytes for DNA isolation were obtained from C.L. (Russell and Weisskopf, 1986).

Probes for an $\mathrm{HBV}$ integration site on chromosome 11p14 (HVBS1, Rogler et al., 1985) were provided by Dr. Rogler. Probes ES1-2 (D11S9, Gusella et al., 1980) and J19.4 (D11S17, Housman et al., 1985) were obtained from D. S. Gerhard. The 0.5-kbp Hincll/SacI fragment of pRS1.2 (Watkins et al., 1987) was used as a probe for FSHB. Plasmid p32-1 (D11S16, Feder et al., 1985) was obtained from the ATCC (Rockville, MD). Probe pTTR is identical to p0.6EH in Boehm et al. (1988) and was subcloned from a $\lambda$ phage obtained by screening a human $M b o I$ partial digest library in EMBL3 with synthetic oligonucleotides prepared according to the published sequence of p0.6EH. The identity of the clone was verified by comparison of restriction sites and mapping against hybrid cell panels.

All other clones used in this study were isolated from different phage libraries and have been described elsewhere (Bruns et al., 1984, 1987; Gessler et al., 1989).

\section{Pulsed-Field Gel Analysis}

Preparation of DNA in agarose blocks and restriction enzyme digestions were performed according to protocols obtained from D. Barlow and $H$. Lehrach (Herrmann et al., 1987) as described previously (Gessler and Bruns, 1988). One percent agarose gels were run in an LKB pulsaphor unit in 0.5 X TBE using the double inhomogeneous field electrodes (Schwartz and Cantor, 1984; Carle and Olsen, 1984) or the CHEF electrode array described by Chu et al. (1986). In some experiments the Rotaphor electrophoresis unit (Immunetics, Cambridge, MA) was used. DNA was transferred to GeneScreen membranes in $0.5 \mathrm{~N} \mathrm{NaOH}, 1.5$ $\mathrm{M} \mathrm{NaCl}$ and immobilized by baking and uv crosslinking (Church and Gilbert, 1984).
Hybridizations were carried out in $0.5 M$ sodium phosphate, pH 7.2, $1 \%$ SDS, $1 \mathrm{mM}$ EDTA, and $50 \mu \mathrm{g} /$ ml salmon sperm DNA at $65^{\circ} \mathrm{C}$ with subsequent washing in $40 \mathrm{mM}$ sodium phosphate, $1 \% \mathrm{SDS}$ at $65^{\circ} \mathrm{C}$ (modified from Church and Gilbert, 1984). Before rehybridization, the filters were stripped in $0.1 \times \mathrm{TE}, 0.1 \%$ SDS for $30 \mathrm{~min}$ at $75-80^{\circ} \mathrm{C}$.

To optimize sizing of fragments, gels were run under a number of different conditions to shift bands into the upper part of the gel where resolution is far greater (region 3 in Vollrath and Davis, 1987). In some instances the switching time was increased during the run time in a linear or quadratic fashion to ensure good resolution over a wider size range (Sor, 1988). Phage $\lambda$ multimers and chromosomes of Saccharomyces cerevisiae and Schizosaccharomyces pombe were used as size markers (Carle and Olsen, 1985; Vollrath and Davis, 1987; Smith et al, 1987). To measure fragment sizes, the filters were hybridized with radioactively labeled $\lambda$ DNA or a fluorescent ruler was placed alongside the ethidium bromide-stained gel during photography to compare the migration distance of fragments with the positions of size markers.

As described by other investigators, size differences due to overloading in parts of the gel and dependence on switching times were observed (Bernards et al., 1986; Burmeister et al., 1988). These were most prevalent when the fragments analyzed were migrating in the lower, more dense and compressed region of the gel. All measurements were therefore taken from gels on which the specific fragments were localized in a less dense and well-resolved region close to size standards. This resulted in reproducible size determinations and consistent partial and double digest size data with an approximate error of $10-15 \%$ between different gels. The paucity of well-defined size markers and the summated lesser experience with fragments greater than 1.5 $\mathrm{Mbp}$ may produce larger errors in this size range.

\section{RESULTS}

\section{Strategy of PFG Mapping}

All the probes used in this study had been mapped on a series of WAGR-related deletions isolated in hybrid cell lines or by gene dosage analysis. This highresolution deletion map allowed us to order the probes into 16 intervals spanning proximal 11p14 to distal $11 p 12$ (Gessler et al., 1989). Starting from this framework, a number of these probes were hybridized with PFG blots prepared from normal lymphoblastoid DNA digested with several rare-cutting restriction enzymes. Size distributions varied considerably among individual probes but generally the enzymes NotI, Sfi I, SacII, BssHII, MluI, NruI, and SalI proved to be the most valuable and reliable, giving fragments in the range of $100 \mathrm{kbp}$ to $3 \mathrm{Mbp}$ in most instances.

To obtain almost complete coverage of the chro- 
mosomal region and to accurately determine the position of the probes, two types of experiments were performed. Double digests with different combinations of enzymes were used to determine the relative order of specific fragments. This identifies the most distal reaching fragments and also narrows the interval for localization of the probe on the shortest single or double digest fragment. Single digests with enzymes producing long fragments were then used to verify linkup between different probes if they shared at least two separate fragments. For the latter type of experiment, the analysis of DNAs from different tissues or cell types proved to be very useful, as all rare-cutting enzymes containing CpG dinucleotides in their recognition sequence show a high degree of polymorphism, likely due to differential methylation in various cell types.

To show identity of fragments recognized by two probes, we employed different sets of electrophoresis conditions to shift the fragments into the regions of high resolution on the gel and hybridized the probes sequentially against the same filter. Compatibility of the local maps from double digests for both probes corroborated the linkup. Double digests furthermore excluded the presence of any sizable interspersed fragments in a number of cases in which continuity between two fragments was not shown by partial digests. In both cases, however, very small fragments may go undetected.

\section{The Proximal Linkup Region}

A summary of the fragment sizes obtained with the probes in different single and double digests is shown in Table 1. Only the two most frequently used double digest combinations are shown. Almost all possible permutations of two enzymes have, however, been useful in at least some instances to precisely determine the relative position of specific fragments. The largest continuously linked region spans approximately $6 \mathrm{Mbp}$ and extends from 508 to E243 (Fig. 1a). The evidence for this is based on multiple shared fragments between adjacent probes. The most valuable long linkup fragments were produced by MluI (508 to CAT, E97 to 151), NruI (540 to E97), and SalI (Cat to TTR, 302 to E243). One example of a sequential hybridization demonstrating the linkup of six probes is shown in Fig. 2. All bands marked by arrows in this figure matched when the autoradiograms were superimposed. This was also seen when the fragments were separated under different electrophoretic conditions to shift their relative positions. The order of probes starting from 508 can be deduced from the pattern of fragments shared with adjacent probes. These results are corroborated by a number of additional linking fragments obtained from digests with $S f i$ I and SalI, listed in Table 1.

Probe 508 had been placed most centromeric on the basis of gene dosage analysis in GM8785 and other cell lines (Gessler et al., 1989). It could be localized close to the centromeric end of a long Mlul fragment which extends far telomeric and includes the catalase gene. An MluI partial digest fragment of $3.5 \mathrm{Mbp}$, also corecognized by these probes, confirmed the linkup in this case.

Probe 540 could not be distinguished from J77-PH on the basis of the PFG pattern observed, but it is located centromeric to J77-PH as deduced from gene dosage analysis in GM7736 (Gessler et al., 1989). Both probes share NotI and NruI fragments with the catalase gene. Double digests of SalI with NotI and Sacll place CAT close to the telomeric end of the $1.5-\mathrm{Mbp}$ NotI fragment.

SalI proved to be very informative to link the catalase gene with probes 277 , E97, and TTR. They share three of four to five different fragments in SalI-digested DNA (Table 1). A similarly complex pattern of bands was observed with MluI and probes E97, TTR, E61, 302,502 , and 151. Different combinations of four major fragments were found in the DNA samples used in Fig. 3 with additional weaker fragments that were not further evaluated. These variations, which are reproducible in multiple DNA preparations from different cell lines, are highly informative for establishing or corroborating linkup between probes. They are most likely due to partial methylation at a number of consecutive sites which inhibit complete digestion. The possibility of a true RFLP hidden in these patterns cannot, however, be excluded.

Probes 302 and 502 produced identical hybridization patterns and their relative order remains unknown. These probes share a Sall fragment and NaeI partial digest fragments with probes 257 and 282 , located on the telomeric side of a cluster of rare-cutting enzyme sites. Probes 257 and 282 have been linked by chro. mosome walking. Likewise the SacII and BssHII fragments identified by E243 have been reached from 282 (M. Gessler, unpublished results). The clusters of rarecutting enzyme sites between 277/E97, E97/TTR, and $151 / 257$ have been mapped extensively on short-range gels and appear to represent true HTF islands with a localized, marked overrepresentation of unmethylated $\mathrm{CpG}$ dinucleotides. The most telomeric extension from E243 is seen with MluI giving a partial digest fragment of $1.3 \mathrm{Mbp}$, similar in size to that of a variant $\mathrm{NruI}$ fragment seen in the H.V. cell line and to NruI partial digest fragments (not shown).

\section{The Linkup Cluster around the FSHB Gene}

A second large continuously linked region extends from probe 495 to 25 and includes the FSHB locus. Probe 495 is located close to a region where most of the rare-cutting enzymes employed have sites (Fig. 1b). These sites seem to be cut very efficiently or alternatively there may be additional sites close by, as we have been unable to obtain partial digest fragments extending significantly centromeric. The linear order of probes 
TABLE 1

Summary of Restriction Fragment Sizes"

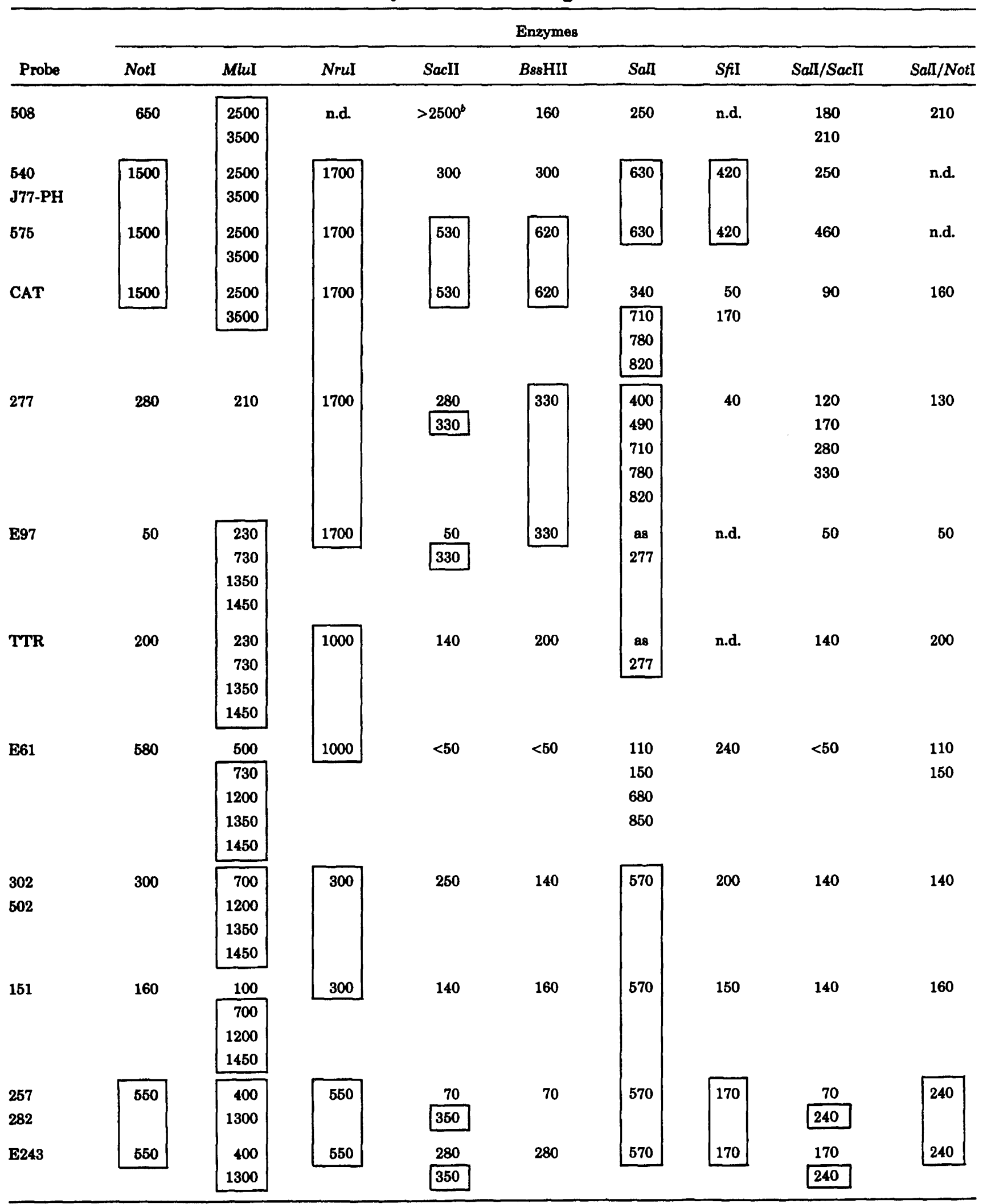


TABLE 1-Continued

\begin{tabular}{|c|c|c|c|c|c|c|c|c|c|}
\hline \multirow[b]{2}{*}{ Probe } & \multicolumn{9}{|c|}{ Enzymes } \\
\hline & NotI & MluI & NruI & SacII & BssHII & SalI & SfiI & Sall/SacII & Sall/NotI \\
\hline \multirow[t]{2}{*}{495} & \multirow[t]{2}{*}{1400} & \multirow[t]{2}{*}{$>4000^{b}$} & 1700 & 340 & \multirow[t]{2}{*}{1400} & 340 & \multirow[t]{2}{*}{410} & \multirow[t]{2}{*}{340} & \multirow[t]{2}{*}{340} \\
\hline & & & 2000 & 1400 & & 360 & & & \\
\hline \multirow[t]{2}{*}{582} & \multirow[t]{2}{*}{1400} & \multirow[t]{2}{*}{$>4000^{b}$} & 1700 & 1100 & \multirow[t]{2}{*}{1400} & 230 & \multirow[t]{2}{*}{170} & \multirow[t]{2}{*}{ n.d. } & \multirow[t]{2}{*}{ n.d. } \\
\hline & & & 2000 & 1400 & & 350 & & & \\
\hline \multirow[t]{2}{*}{403} & \multirow[t]{2}{*}{1400} & \multirow[t]{2}{*}{$>4000^{b}$} & 1700 & 1100 & \multirow[t]{2}{*}{1400} & 130 & \multirow[t]{2}{*}{130} & \multirow[t]{2}{*}{ n.d. } & \multirow[t]{2}{*}{ n.d. } \\
\hline & & & 2000 & 1400 & & 350 & & & \\
\hline 570 & 1400 & $>4000^{b}$ & 1700 & 1100 & 1400 & 200 & 350 & n.d. & n.d. \\
\hline & & & 2000 & 1400 & & & & & \\
\hline D11S16 & 1400 & $>4000^{b}$ & 1700 & 1100 & 1400 & 120 & 520 & 120 & 120 \\
\hline & & & 2000 & 1400 & & 190 & & 140 & 140 \\
\hline 239 & 3100 & $>4000^{b}$ & 1700 & 120 & 2600 & 70 & 520 & 50 & 50 \\
\hline & & & 2000 & 2200 & & 190 & & 70 & 70 \\
\hline 1 & 3100 & $>4000^{b}$ & 380 & 2100 & 2600 & 310 & 850 & 310 & n.d. \\
\hline FSHB & & & 2000 & 2200 & & & & & \\
\hline 202 & 3100 & $>4000^{b}$ & 380 & 2100 & 2600 & 430 & 850 & n.d. & n.d. \\
\hline & & & 2000 & 2200 & & 550 & & & \\
\hline 74 & 3100 & $>4000^{b}$ & n.d. & 2100 & 2600 & 120 & 850 & 120 & n.d. \\
\hline & & & & 2200 & & 190 & & 190 & \\
\hline & & & & & & 210 & & 210 & \\
\hline 291 & 3100 & $>4000^{b}$ & n.d. & 2100 & 2600 & 80 & 850 & 80 & n.d. \\
\hline & & & & 2200 & & 100 & & 100 & \\
\hline & & & & & & 190 & & 190 & \\
\hline & & & & & & 210 & & 210 & \\
\hline 181 & 3100 & $>4000^{b}$ & n.d. & 2100 & 2600 & 390 & 360 & n.d. & n.d. \\
\hline 475 & & & & 2200 & & 560 & & & \\
\hline 164 & 3100 & $>4000^{b}$ & n.d. & 900 & 2600 & 550 & 660 & 550 & n.d. \\
\hline & & & & & & 800 & & 650 & \\
\hline 25 & 3100 & $>4000^{b}$ & $-^{c}$ & 900 & 820 & 240 & 660 & 210 & 230 \\
\hline & & & & & & 280 & & 250 & 270 \\
\hline E136 & $>4000^{b}$ & 3500 & $-c$ & 1300 & 350 & 340 & 370 & 340 & 340 \\
\hline & & & & & & 900 & & 440 & 520 \\
\hline & & & & & & & & 520 & \\
\hline HVBS1 & $>4000^{b}$ & 3500 & $-c$ & 1300 & 2100 & 125 & 210 & 125 & n.d. \\
\hline & & & & . & 2400 & & & & \\
\hline 109 & $>4000^{b}$ & 3500 & $-c$ & 1300 & 2100 & 500 & 150 & 380 & n.d. \\
\hline & & & & & 2400 & & & & \\
\hline 113 & $>4000^{b}$ & 3500 & $-^{\circ}$ & $>4000^{b}$ & 2100 & 360 & 420 & 360 & n.d. \\
\hline & & & & & 2400 & & & & \\
\hline D11S17 & $>4000^{b}$ & 3500 & $-c$ & $>4000^{b}$ & 330 & 220 & 570 & 220 & 220 \\
\hline & & & & & 2400 & 330 & & 330 & 330 \\
\hline
\end{tabular}

- Fragment sizes are given in kilobase pairs. All measurements are derived from cell line 6697, with the exception of additional variant bands for MluI (E97-151) and Sach (239-181/475) shown in Figs. 3 and 4.

'No distinct fragment could be resolved. Hybridization to loading slots or limiting mobility region was observed to a varying degree.

c Accurate NruI fragment sizes have not yet been determined. 


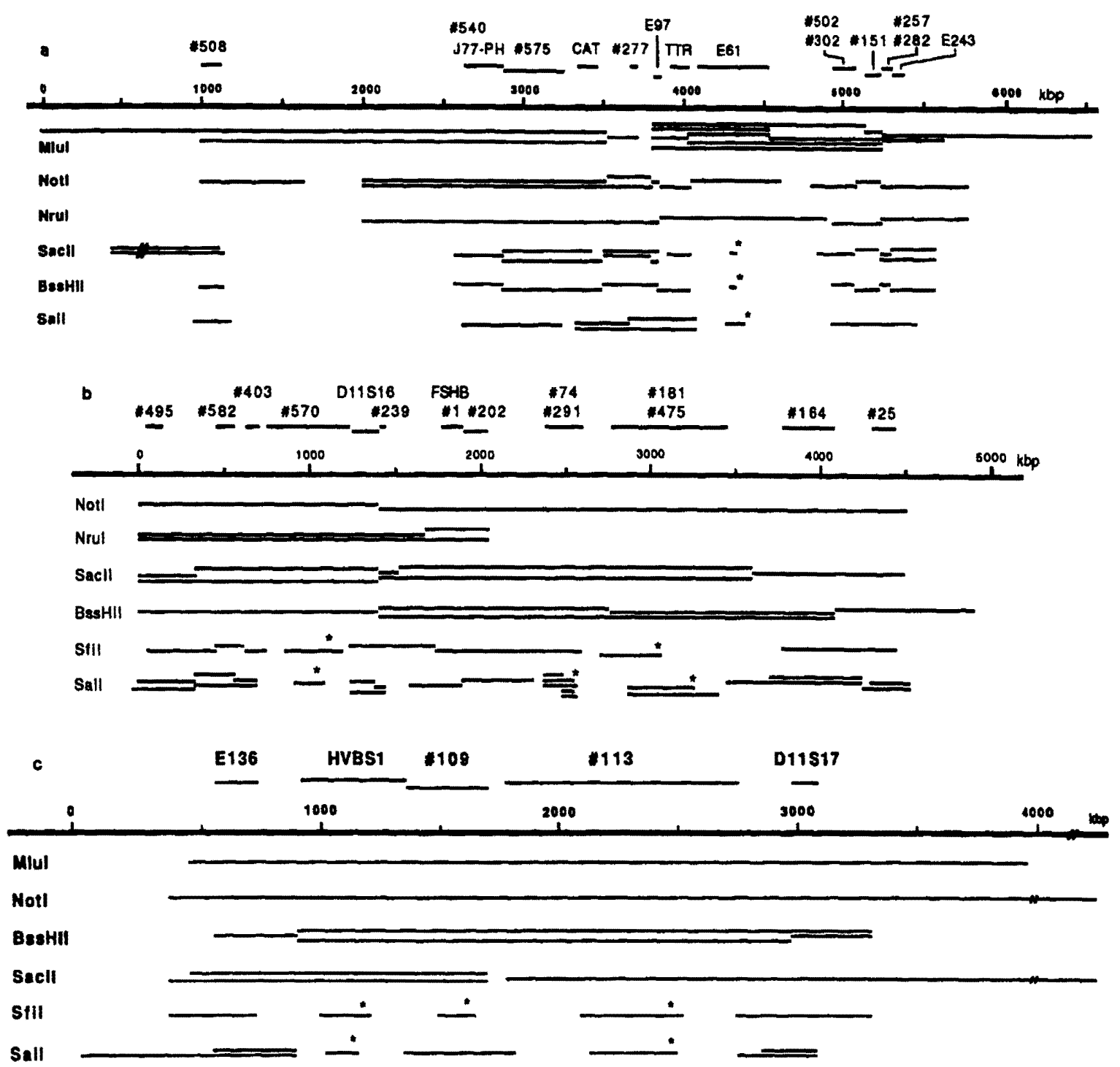

FIG. 1. Long-range restriction maps around (a) CAT, (b) FSHB, and (c) HVBS1. Fragment sizes for 6697 DNA as listed in Table 1 were used together with sizes of a large number of fragments produced by double digests (not shown) to construct these maps. The probe numbers are listed in the order from centromere to telomere, with solid bars indicating the shortest possible interval for their location as deduced from double digests. Horizontal lines below the scale bar represent restriction fragments generated by the respective enzymes listed on the left side. In several instances additional fragments that were only seen in other DNA samples are included (MluI E97/151; BssHII 239/164; see Figs. 3 and 5). For fragments marked by asterisks the precise position could not be determined due to the lack of informative double digests. The 1.7. Mbp Nrul fragment for CAT was seen in 6697 DNA. Other cell lines have a 650-kbp fragment that was not mapped further. The orientation of the different Sall fragments recognized by 74/291 is not known. For 181/475 the positions of the Sfi I and Sall fragments relative to each other were determined by double digests. Their orientation with respect to surrounding probes, however, is based on preliminary evidence from deletion mapping and remains provisional. The multiple SalI partial digest products detected by CAT/TTR and E61 have not been mapped.

495,582 , and 403 has been established from SalI partial digests and shared ClaI and PaeR7I fragments. These probes hybridize to NotI, BssHII, and partial SacII fragments of the same size (1.4 Mbp) which are corecognized by 570 and D11S16. An HTF island separates D11S16 and 239, which are linked by Sfi I and SalI fragments. From there, long NotI, BssHII, and SacII fragments extend telomeric for 2.2 to $3.1 \mathrm{Mbp}$ (Figs. 4 and 5). The variation in partially digested fragments with SacII in DNA samples from different cell lines provides information about the relative order of probes. This has been confirmed and extended with other enzymes. Five of these probes are located on a $850-\mathrm{kbp}$ $S f i$ I fragment that can be subdivided using $\mathrm{NruI}$ and SalI in single and double digests. For 1/FSHB, 74/291, and $181 / 475$, however, the order within each pair could not be established. Although different on conventional Southern blots, these probe pairs shared most or all 


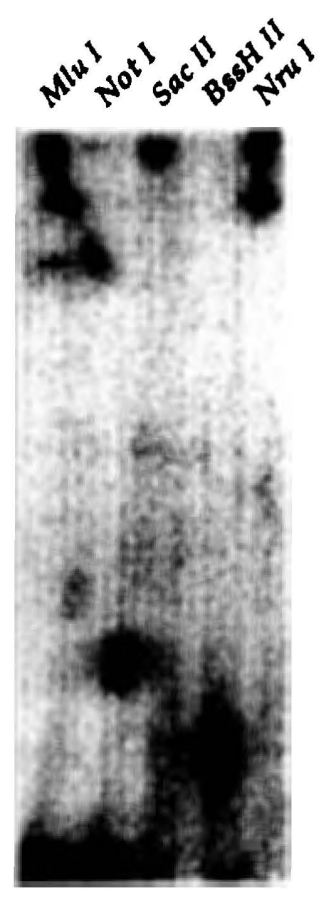

$+508$

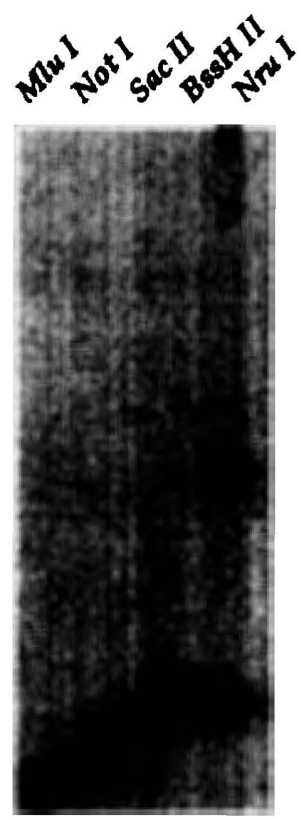

$+277$

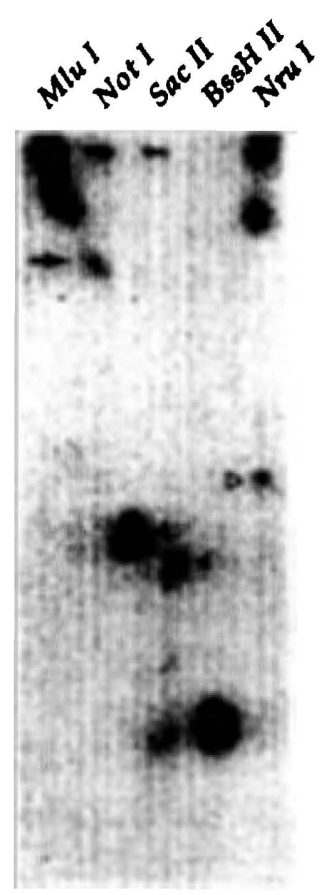

J77-PH

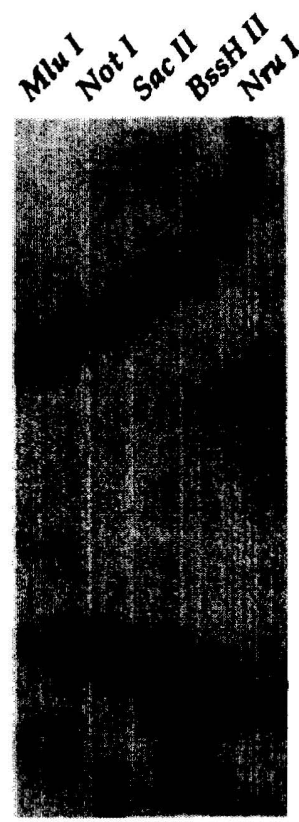

E 97

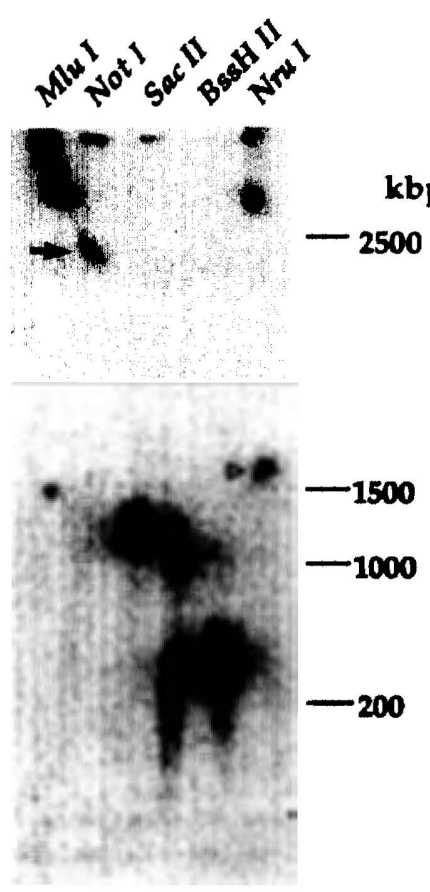

CAT

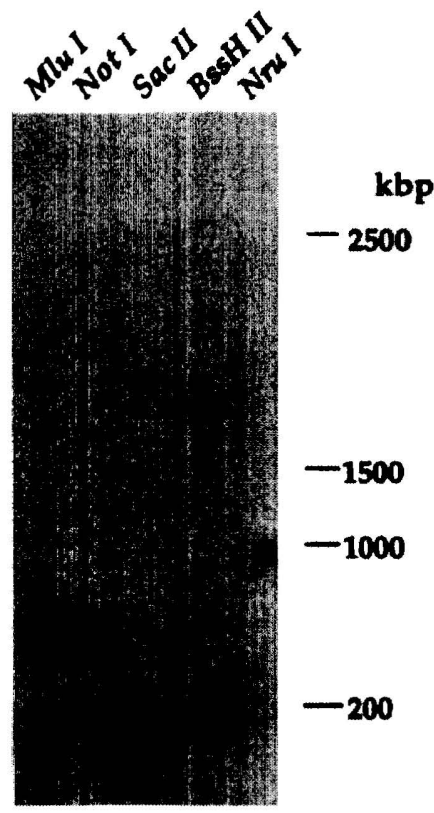

TTR

FIG. 2. Linkup of centromeric probes surrounding CAT. DNA from 6697 cells, digested with the enzymes indicatod, was separated in an LKB pulsaphor apparatus at $220 \mathrm{~V}$ with $300-8$ switching time at $15^{\circ} \mathrm{C}$ for 2.5 days and transferred to GeneScreen membranes by alkaline blotting. Hybridizations with the probes listed below the autoradiograms were carried out sequentially and the filters were stripped before reuse to remove radioactive probe. Arrows point to restriction fragments corecognized by different probes when the autoradiograms were superimposed. The enzyme SacII did not cut to completion here and revealed partial digest products with most probes. 


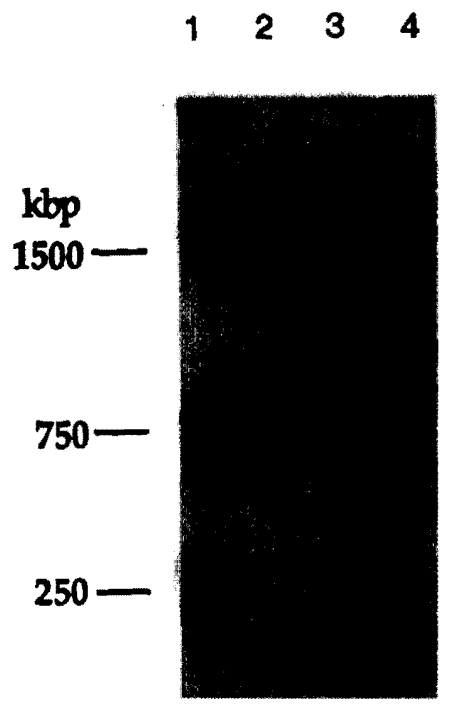

E97

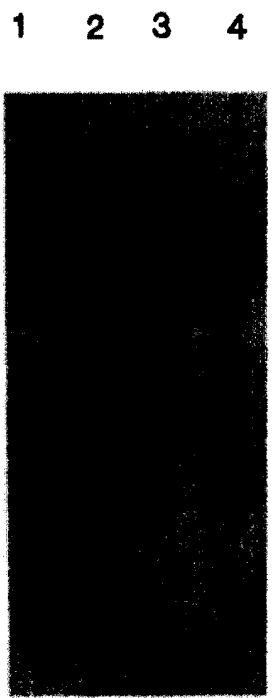

E6 1
1

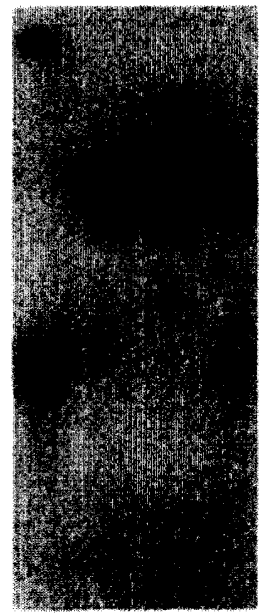

$+302$ $\begin{array}{llll}1 & 2 & 3 & 4\end{array}$

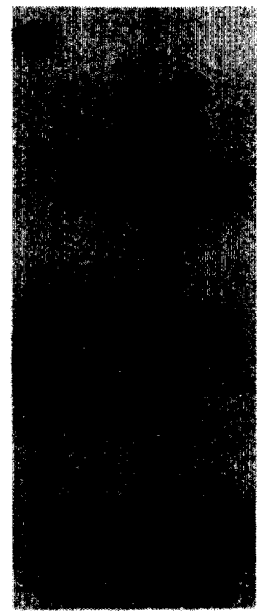

151

FIG. 3. Linkup with variant MluI fragments. Four DNA samples, 6697 (1), GM3809 (2), C.L. (3), and GM5297 (4), were digested to completion with MluI. Electrophoresis was carried out in an LKB pulsaphor apparatus at $220 \mathrm{~V}$ with alternating switching times of 100,200 , and 300 s at $10^{\circ} \mathrm{C}$ for $48 \mathrm{~h}$. After transfer to GeneScreen, the filter was sequentially hybridized with probes E97, E61, 302, and 151. The probes detect approximately $1450 \mathrm{kbp}$ of DNA, represented by the top band in lanes 2-4, that can be cut into shorter subfragmento depending on the accessibility of three major internal Mlul sites located between the probes as shown in Fig. 1a. The additional weakly hybridizing fragments of 700-1000 kbp seen in lanes 2-4 were not further evaluated. Patient C.L. is hemizygously deleted for this entire region (21), thus ruling out a RFLP accounting for the variant fragments. The slightly lower mobility of the top band in that sample is likely due to the preparation of the DNA from a blood sample.

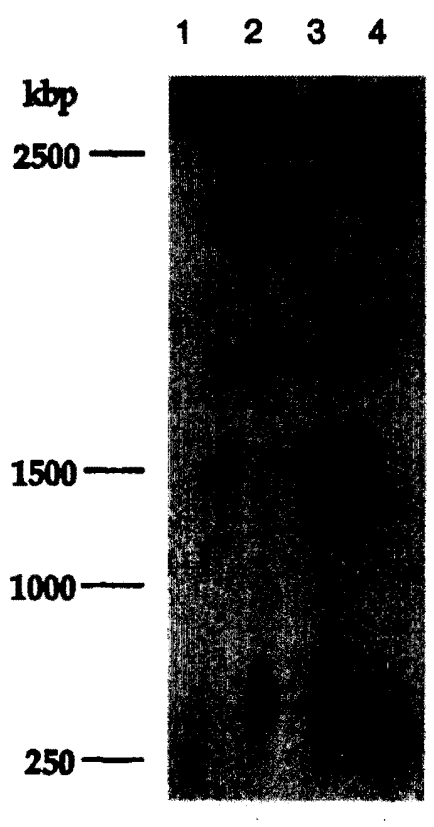

$\$ 239$ $\begin{array}{llll}1 & 2 & 3 & 4\end{array}$

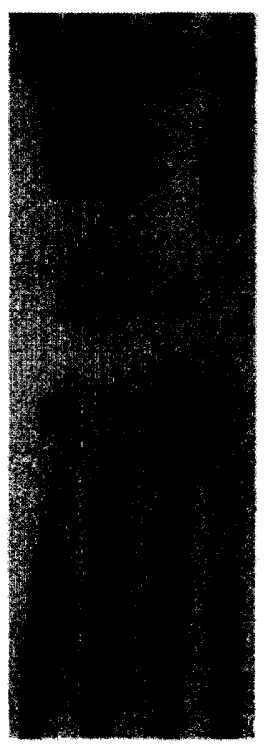

FSHB
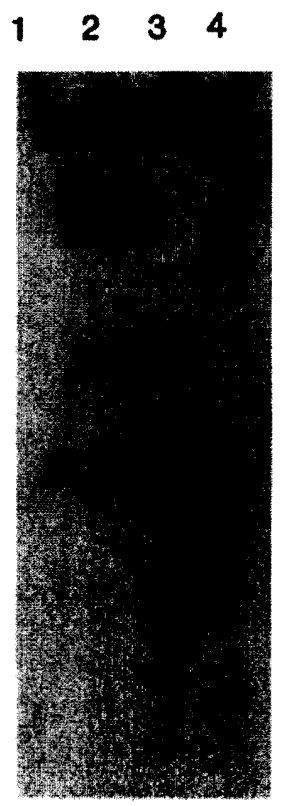

$+281$
$1 \quad 2 \quad 3 \quad 4$

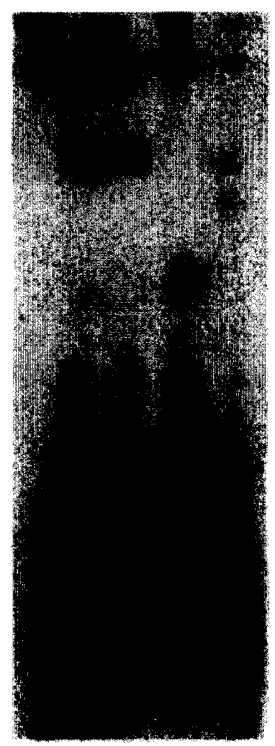

$+181$

FIG. 4. Variation in Sacll cutting sites orders probes around FSHB. DNA from GM7427 (1), 6697 (2), H.V. (3), and GM4613 (4), digested with SacII, was separated as described in Fig. 2. Hybridization with the probes indicated below the autoradiograms revealed major variant fragments in H.V. and GM4613 that establish the order from 239 to 181 . The largest fragment detected in lane 3 is corecognized by 239 , FSHB, and 291. The next smaller fragment is only shared by 239 and FSHB. Probe 239 detects a very small fragment in lane 4 (120 kbp on short-range blots), whereas the three other probes detect a 2100-kbp fragment in addition to the 2200-kbp fragment, also soen in lanes 1 and 2. The exact position of the variant Sacll sites in H.V. and other weakly hybridizing fragments bave not been determined. 


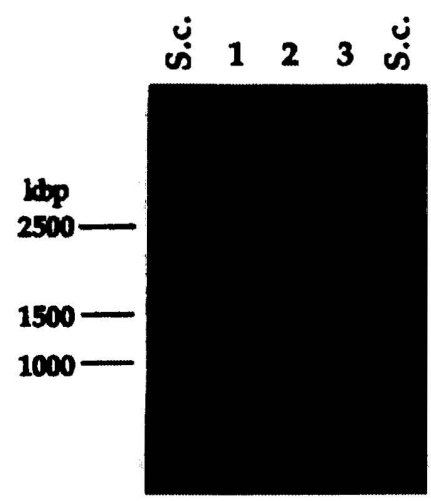

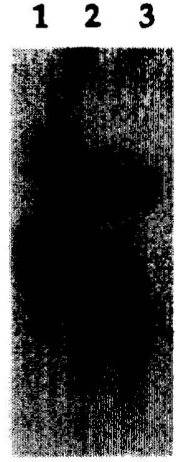

$+239$
123

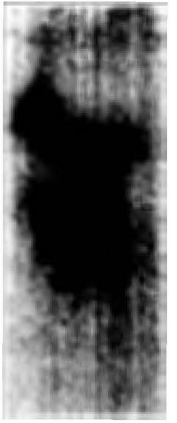

$+291$
123

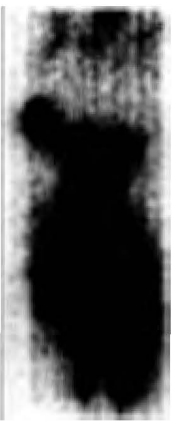

$+181$
123

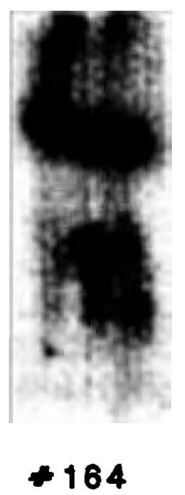

FIG. 5. Linkup with BssHII. DNA from the human-hamster hybrid line G156E5, containing a normal human chromosome 11 homolog (1), H.V. (2), and 6697 (3) was digestod with BssHII. PFGE was performed with $170 \mathrm{~V}$ and $600-8$ switching time for $24 \mathrm{~h}$, followed by $900 \mathrm{~s}$ for $36 \mathrm{~h}$ at $15^{\circ} \mathrm{C}$ with $S$. cerevisiae chromosomes (S.c.) as size markers. The ethidium bromide staining of the gel is shown on the left side. All four probes used in sequential hybridizations detect the same band of approximately $2600 \mathrm{kbp}$. The upshift of the fragment in lane 1 was seen reproducibly with other combinations of probes and enzymes and is characteristic of this hybrid line under the conditions used. The additional fragment seen in lane 1 with 239 represents cross-hybridizing hamster DNA. Variant bands were again seen in H.V. DNA (lane 2). Probes 239 and 291 detect the same fragment, whereas 181 and 164 detect a different, slightly smaller fragment that orients these probes.

rare-cutter fragments and did not produce informative double digest fragments. The restriction map around 164 and 25 on the telomeric end of this cluster has been described (Gessler and Bruns, 1988).

\section{The Telomeric Linkup Cluster Including HVBSI}

The HVBS1 marker is localized on a 3.5-Mbp MluI fragment (Fig. 6), which is corecognized by four other probes (E136, 109, 113, and D11S17). One of these, E136, is close to the centromeric end of this fragment where a number of sites for other rare-cutting enzymes were found (Fig. 1c). The SacII fragment for 113 and D11S17 and the Not I fragment for this entire area are likely larger than $4 \mathrm{Mbp}$. Resolving these fragments on gels with extremely long switching times (Orbach et al., 1988) may permit scanning of a large fraction of 11 p14 for gross rearrangements.

\section{Distribution of Unmethylated CpG Dinucleotides}

The entire mapped area covers approximately 15.4 $\mathrm{Mbp}$, reaching from proximal $11 \mathrm{p} 14$ to distal $11 \mathrm{p} 12$. An enormous variation in average fragment sizes and therefore in the frequency of sites is observed for enzymes containing CpG dinucleotides. As these enzymes are sensitive to cytosine methylation, a combined pat-

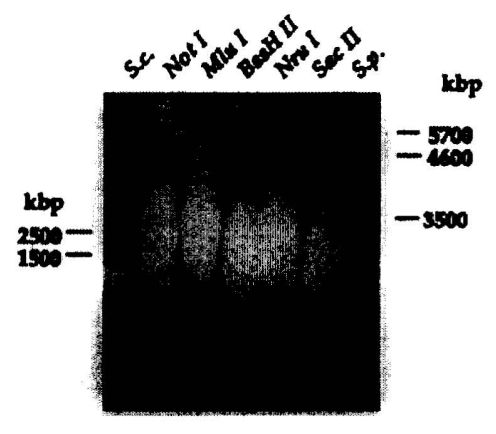

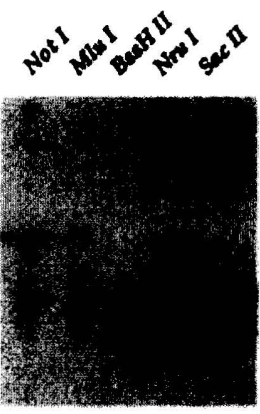

E 136

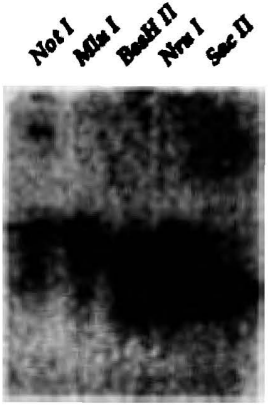

HVBS 1

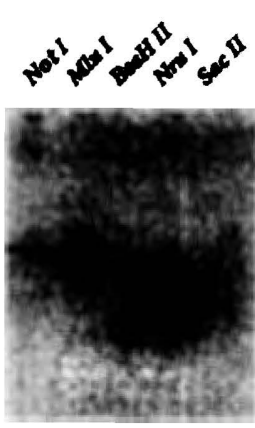

D11S17

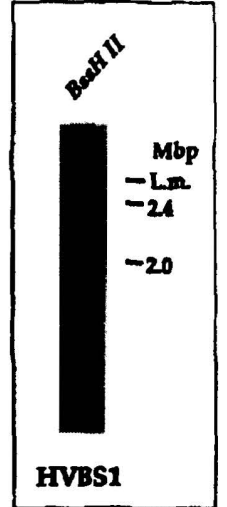

FIG. 6. Linkup of probes around the HVBS1 locus. To resolve larger fragments, 6697 DNA cut with the enzymes indicated was separated in a Rotaphor electrophoresis unit at $50 \mathrm{~V}$ with $3600-8$ switching time at $15^{\circ} \mathrm{C}$ for 7 days. Size markers were $S$. cerevisiae (S.c.) and S. pombe (8.p.) chromosomes. All three probes used detected an MluI fragment of $3.5 \mathrm{Mbp}$ in size marked by arrowg. Probes E136 and HVBS1 also share a Sacll fragment of $1.3 \mathrm{Mbp}$. HVBS1 identifies a tight BssHII doublet that can be resolved using electrophoresis conditions described in Fig. 2 (see insert on the right side). Fragments of 2.0 and $2.4 \mathrm{Mbp}$ are separated below the region of limiting mobility (L.m.). Probes HVBS1 and D11S17 corecognize the BssHII partial digest fragment of $2.4 \mathrm{Mbp}$. Although poorly reproduced in the D11S17 picture, the partial digest is clearly seen on the original autoradiogram and in repeat experiments. Digests with Nrul frequently did not produce distinct bands with these probes. 
tern resulting from restriction site occurrence and local degree of methylation is actually observed. The highest density of unmethylated sites is found between the catalase gene and probe E243 and could perhaps extend telomeric for a short stretch, as mapping is incomplete in this region (Fig. 7). The average Not I fragment size in this region is only a few hundred kilobase pairs; $S a c I I$ and $B s s H I I$ frequently produce fragment sizes of $250 \mathrm{kbp}$ or less. Outside this region and especially distal to 239 , the density of unmethylated sites for rare-cutting enzymes is much lower, resulting in fragment sizes of several megabase pairs.

A clustering of sites is already obvious from the maps and most prominent between CAT/TTR, 151/257, D11S16/239, and close to 508, 495, and E136 (Figs. 1a, $1 \mathrm{~b}$, and 7). More precise mapping on short-range gels using double digests with SalI or Sfi I indicated that most of these clustered sites are within less than 20 kbp. It is possible that they could be within $2 \mathrm{kbp}$ as described for a number of sequences identified as HTF islands by Brown and Bird (1986). The enzymes Sfi I and SalI are particularly useful for precise mapping of $\mathrm{CpG}$ clusters because their cutting sites are not overrepresented in HTF islands.

\section{DISCUSSION}

Pulsed-field gel electrophoresis is a powerful tool with which to take the step from cytogenetic analysis and deletion mapping to a physical mapping of a chromosomal region. We have previously isolated a large number of random probes that map to a cytogenetically detected WAGR deletion that had been isolated in a somatic cell hybrid line (Bruns et al., 1987). By analysis of additional overlapping deletions, the WAGR deletion region has been subdivided into 16 individual intervals, each definable by one or more deletion boundaries as well as by particular probe subsets, and specific subregions have been correlated with phenotypic features (Gessler et al., 1989).

To define the physical relationship of the probes and to develop a molecular framework of this region, a longrange restriction map has been constructed by PFGE analysis. Twenty-nine probes plus the reference loci CAT, D11S16, FSHB, HVBS1, and D11S17 and the 11 p13 T-cell translocation breakpoint region (Boehm et al., 1988) have been incorporated into this map, which consists of three large clusters spanning more than $15 \mathrm{Mbp}$ in total. With few exceptions, the 35 probes produced unique size patterns for the seven enzymes used throughout the study. Linkup between probes was considered to be established only if they shared at least two fragments consistent with local restriction maps derived from double digests and with probe order derived from prior deletion mapping.

The construction of the map is based on the fragment sizes observed in DNA from the lymphoblastoid cell

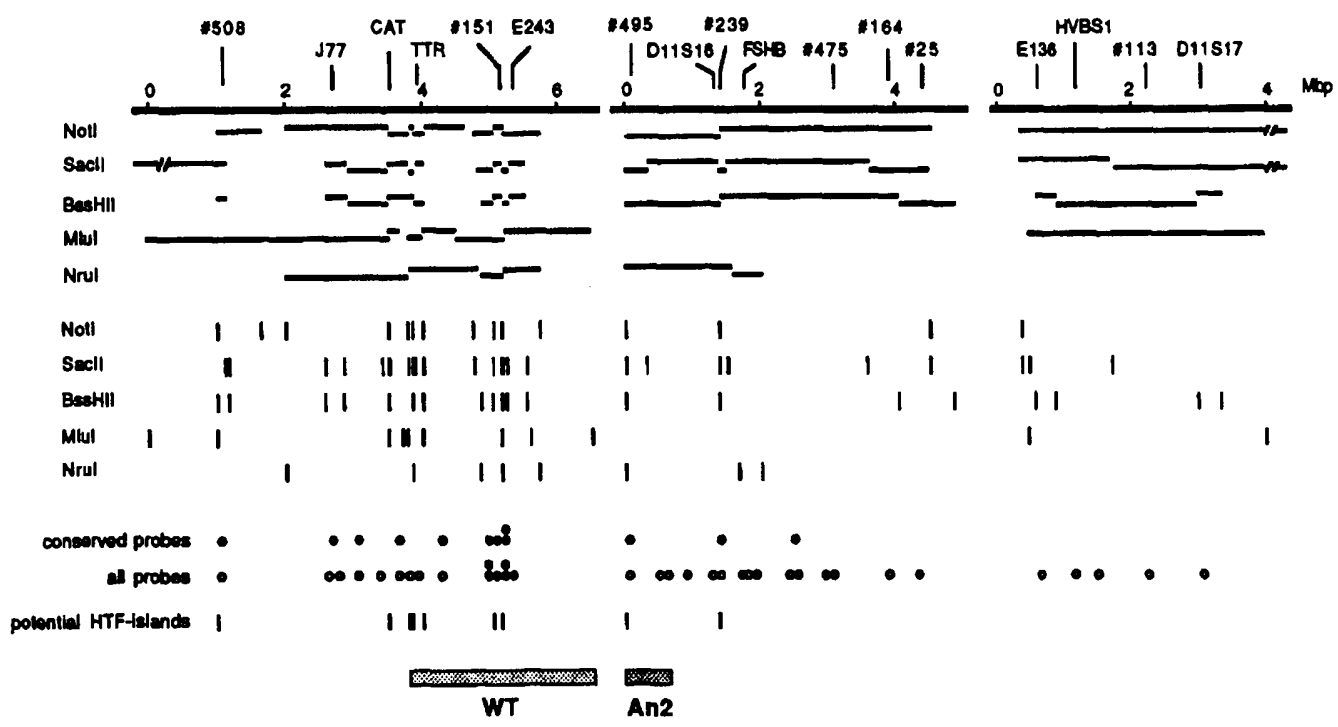

FIG. 7. The physical map around the WAGR complex. Simplified versions of the restriction maps shown in Fig. 1 are lined up in order from centromere to telomere. The restriction fragments are drawn as horizontal lines to show the degree of coverage for each of the enzymes. Only enzymes with preferential cutting in HTF islands (34) are shown. Below the fragments the observed cutting sites for all enzymes are indicated to highlight the uneven distribution of these sites. As seen from the upper part of the figure, there may be additional sites, especially for SacII and BssHII, in areas where complete coverage was not obtained (e.g., 508/J77, E61, and distal to E243). The positions of all probes used are marked by open circles. Generally, the center of the localization bars in Fig. 1 was used for positioning. All probes that show conservation in rodent DNA $(8,21)$ are indicated by solid circles. Potential HTF islands were defined as areas where at least three of the five enzymes used have sites within $20 \mathrm{kbp}$ or less, depending on the resolution achieved. The shaded bores represent the smallest region of overlap for the Wilms tumor and aniridia genes as defined by deletion mapping (21). 
line 6697 , supplemented in places with additional information derived from six other lymphoblastoid and fibroblast cell lines. At least $85 \%$ of the map has been confirmed in these cell lines, with minor variations likely due to methylation differences and possibly RFLPs.

In only two instances were we unable to find linking fragments between neighboring probes. With an average spacing of only $300-400 \mathrm{kbp}$ between the random probes, large gaps in this region would not be expected, although the probe distribution does not appear to be completely random. Rather, the discontinuities may be the result of clustered restriction sites for the enzymes used, which makes it difficult to find fragments spanning these sequences. This type of clustering is especially obvious on the centromeric side of probe 495 and the telomeric side of probe 25 . It is quite possible that the 1.3-Mbp MluI fragment seen by probe 243 and the variant or partial NruI fragments of similar size seen in a number of DNA samples may terminate at this cluster of sites near probe 495 .

Most of the probes used in this study were isolated from recombinant phage initially identified by hybridization with labeled total human DNA. No significant bias against a certain region may be expected with this strategy. However, a higher probe density is found close to CAT, between 302 and E243 and around FSHB. This skewing may have been introduced during construction of the library or in subsequent amplification steps. It is also possible, however, that this reflects a difference in the abundance of highly repetitive sequences, used to identify the clones, along the chromosome as suggested by the in situ hybridization studies of Korenberg and Rykowski (1988).

Interestingly, the distribution of sites for the rarecutting enzymes used in this study reveals a markedly higher density in certain places, particularly between the catalase gene and probe E243 or 239 (Fig. 7). In a number of instances several sites appear to be located in very close proximity as judged from short-range PFGE blots, suggesting that they identify putative HTF islands. Localization of these clusters is a powerful method to target expressed sequences, as HTF islands frequently represent the 5 ' ends of certain types of genes (Bird, 1986; Lindsay and Bird, 1987). We may, therefore, have localized several potential genes on our map. One of these is likely to be the aniridia gene, as we have localized the breakpoint of a chromosome 11 translocation associated with familial aniridia (Simola et al., 1983) close to probe 495 using PFGE (Gessler et al., submitted).

A second interesting area is defined by the TTR probe, which marks a frequent site for translocation breakpoints involving the T-cell receptor locus observed in certain types of T-ALL (Boehm et al., 1988). This localizes a tumor-specific translocation breakpoint within the region frequently affected by deletions in WAGR patients. The TTR probe is surrounded by close HTF islands, one of which may be the 5 ' end of a gene involved in T-ALL tumorigenesis.

Deletion mapping in different WAGR cell lines has delineated the smallest region of overlap for the loci implicated in Wilms tumor and genitourinary abnormalities, spanning probes E97 to E243 (Gessler et al., 1989). There are a number of potential HTF islands and conserved sequence probes located in this region. Analysis of DNA samples from individuals with genitourinary abnormalities or from Wilms tumors by PFGE analysis for small deletions or other cytogenetically undetected rearrangements in this region may ultimately lead to the identification of the underlying genetic loci. The feasibility of this approach has been documented already by the cloning of the breakpoints of two related chromosome rearrangements, an AGR deletion (Gessler and Bruns, 1988) and a translocation associated with familial aniridia (Gessler et al., submitted), after detection by PFGE analysis.

The detailed restriction map permits a very precise positioning of chromosomal breakpoints. This facilitates their identification by molecular cloning techniques and provides estimates of physical sizes for deletions. The multiplicity of restriction site and probe distance relationships defined by the map establishes a framework for future cloning of the entire chromosomal region.

Some clues about the functional organization of whole chromosomal regions can be drawn from the current map. The overabundance and clustering of rare cutter sites between CAT and 239, an area corresponding to chromosome band p13, are consistent with the hypothesis that Giemsa-light bands like 11p13 are more $\mathrm{G} / \mathrm{C}$ rich and contain a higher density of HTF islands (Bernardi et al., 1985; Holmquist, 1987; Burmeister et al., 1988). On the other hand, Giemsa-dark bands like 11p14, represented by the region distal to FSHB, are more $\mathrm{A} / \mathrm{T}$ rich and have only few rare-cutter sites.

The distribution of conserved segments among the set of random probes used appears to show a similar distortion. Within the proximal region more than half of the probes show conservation, whereas for probes from the telomeric part of the map this is almost never observed. These data suggest that specific chromosomal areas contain a higher density of genes or at least of genes that have been conserved during evolution. A higher concentration of expressed and conserved sequences within early replicating DNA and G/C-rich isochores had been previously described (Goldman et al., 1984; Bernardi et al., 1985). As G/C-rich and A/Trich isochores have recently been correlated with Giemsa-light and -dark bands, respectively (Korenberg and Rykowski, 1988), the skewed distribution of conserved sequence probes along the map of the WAGR 
deletion region likely further reflects the chromosome banding structure of the area.

After completion of this manuscript, Compton et al. (1988) reported a physical map of the Wilms tumoraniridia region prepared with the enzymes NotI and Mlul. Although independent probe banks and unrelated cell lines were used, the NotI and MluI fragment sizes, as well as the fragment arrangements, match well in the critical area of overlap of WAGR deletions. The data of Compton et al. (1988) support the speculation that the MluI fragment recognized by probe E243 (Figs. $1 a$ and 7) extends telomeric up to the region of rarecutter sites proximal to 495 . The two linkup clusters described in this report can thereby be joined into a detailed and continuous map of $11.5 \mathrm{Mbp}$ which encompasses the WAGR deletion region.

\section{ACKNOWLEDGMENTS}

We thank Dr. L. Russell for providing a venous blood sample from patient C.L. and Dr. M. Lalande for S. pombe chromosomes embedded in agarose. This work was supported by NIH Grant GM 34988. M.G. is a recipient of a postdoctoral followship of the Deutsche Forschungsgemeinschaft through the University of Giessen F.R.G.

\section{REFERENCES}

1. Bernardi, G., Oloffson, B., Fit.jpsk1, J., Zerial, M., Salinas, J., CUNY, G., MBUNIER-Rotival, M., AND RODIER, F. (1985). The mosaic genome of warm-blooded vertebrates. Science 228: 953-958.

2. Bernards, A., KoOTER, J. M., MiChELS, P. A. M., MobeRTS, R. M. P., AND BORST, P. (1986). Pulsed field gradient electrophoresis of DNA digested in agarose allows the sizing of the large duplication unit of a surface antigen gene in trypanosomes. Gene 42: 313-322.

3. BIRD, A. P. (1986). CpG-rich islands and the function of DNA methylation. Nature (London) 321: 209-213.

4. BozhM, T., BULUWELA, L., Williams, D., WhIte, L., AND RABBITTS, T. H. (1988). A cluster of chromosome 11 p13 translocations found via distinct $D-D$ and $D-D-J$ rearrangements of the human $\mathrm{T}$ cell receptor delta chain gene. EMBO J. 7: 2011-2017.

5. BRESLOW, N. E., AND BECKWITH, J. B. (1982). Epidemiological features of Wilms' tumor: Results of the National Wilms' Tumor Study. J. Nath. Cancer Inst. 68: 429-441.

6. BRoWN, W. R. A., AND BIRD, A. P. (1986). Long-range restriction site mapping of mammalian genomic DNA. Nature (London) 322: 477-481.

7. Bruns, G. A. P., Glaser, T., Gusella, J. F., Housman, D. E., AND ORKIN, S. H. (1984). Chromosome 11 probes identified with a catalase oligonucleotide. Amer. J. Hum. Genet. 36: 25S.

8. Bruns, G. A. P., BARnes, S. D., Gessler, M., Brennick, J. B., AND WEINER, M. J. (1987). DNA probes for chromosome 11 and the WAGR deletion. Cytogenet. Cell Genet. 46: 588.

9. BURMEISTER, M., AND LEHRACH, H. (1986). Long-range restriction map around the Duchenne muscular dystrophy gene. Nature (London) 324: 582-585.

10. BURMEISTER, M., MONACO, A. P., GLLARD, E. F., VAN OMMMEN, G. J., Affara, N. A., Ferguson-SmTth, M. A., Kunkel,
L. M., AND LEHRACH, H. (1988). A 10-megabase physical map of human Xp21, including the Duchenne muscular dystrophy gene. Genomics 2: 189-202.

11. Carle, G. F., AND Olson, M. V. (1984). Separation of chromosomal DNA from yeast by orthogonal-field-alternation gel electrophoresis. Nucleic Acids Res. 12: 5947-5664.

12. CARLE, G. F., AND OLSON, M. V. (1985). An electrophoretic karyotype for yeast. Proc. Nath. Acad. Sci. USA 82: 3756-3760.

13. ChU, G., Vollarath, D., AND Davis, R. W. (1986). Separation of large DNA molecules by contour-clamped homogeneous electric fields. Science 234: 1582-1585.

14. CHURCH, G. M., AND GILBERT, W. (1984). Genomic sequencing. Proc. Natl. Acad. Sci. USA 81: 1991-1995.

15. Compton, D. A., Weil, M. M., Jones, C., Riccardi, V. M., STRONG, L. C., AND SAUNDERS, G. F. (1988). Long range physical map of the Wilms' tumor-aniridia region on human chromosome 11. Cell 55: 827-836.

16. DAvis, L. M., Byers, M. G., FuKushima, Y., QIN, S., NoWAK, N. J., ScoGGIN, C., AND SHows, T. B. (1988). Four new DNA markers are assigned to the WAGR region of 11p13: Isolation and regional aseignment of 112 chromosome 11 anonymous DNA segments. Genomics 3: 264-271.

17. DRUMM, M. L., SMITh, C. L., DEAN, M., Cole, J. L., LANUZZ, M. C., AND Collins, F. S. (1988). Physical mapping of the cystic fibrosis region by pulsed-field gel electrophoresis. $G e$ nomics 2: $346-354$.

18. Fearon, E. R., Vogelstein, B., aNd Feingerg, A. P. (1984). Somatic deletion and duplication of genes on chromosome 11 in Wilms' tumors. Nature (London) 309: 176-178.

19. Feder, J., Yen, L., Wusman, E., WaNG, L., Wilkins, L., SCHRODER, J., SPURR, N., CANN, H., BLUMENBERG, M., AND CAVAlLI-SForza, L. L. (1985). A systematic approach for detecting high-frequency restriction fragment length polymorphisms using large genomic probes. Amer. J. Hum. Genet. 37: 635-649.

20. Francke, U., Holmes, L. B., AtKins, L., AND Riccardi, V. M. (1979). Aniridia-Wilms' tumor association: Evidence for specific deletion of 11p13. Cytogenet. Cell Genet. 24: 185-192.

21. Gessler, M., Thomas, G. H., Coulluin, P., Junien, C., MCGILLIVRAY, B. C., HAYDEN, M., JASCHEK, G., AND BRUNS, G. A. P. (1989). A deletion map of the WAGR region on chromosome 11. Amer. J. Hum. Genet., 44: 486-495.

22. Gessler, M., AND BRUNS, G. A. P. (1988). Molecular mapping and cloning of the breakpoints of a chromosome 11p14.1-p13 deletion associated with the AGR syndrome. Genomics 3: 117123.

23. Glaser, T., Lewis, W. H., Bruns, G. A. P., Watkins, P. C., Rogler, C. E., SHOWS, T. B., PoWERS, V. E., WILLARD, H. F., GogueN, J. M., SimolA, K. O. J., AND HousmaN, D. E. (1986). The beta-subunit of follicle-stimulating hormone is deleted in patients with aniridia and Wilms' tumor, allowing a further definition of the WAGR locus. Nature (London) 321: 882-887.

24. Goldman, M. A., Holmquist, G. P., Gray, M. C., Caston, L. A., AND NAG, A. (1984). Replication timing of genes and middle repetitive sequences. Science 224: 686-692.

25. Gusella, J. F., KeYs, C., Vasaranyi-Breiner, A., KaO, F.-T., Jones, C., PUCK, T. T., AND Housman, D. (1980). Isolation and localization of DNA segments from specific human chromosomes. Proc. Nath. Acad. Sci. USA 77: 2829-2833.

26. HerrmanN, B. G., BarLow, D. P., AND Lehrach, H. (1987). A large inverted duplication allows homologous recombination between chromosomes heterozygous for the proximal $t$ complex inversion. Cell 48: 813-825.

27. HoLMQUIST, G. P. (1987). Role of replication time in the control 
of tissue specific gene expression. Amer. J. Hum. Genet. 40: 151-173.

28. Housman, D. E., GrRhard, D. S., Glaser, T., AND Jones, C. (1985). Mapping of chromosome 11p by linkage and somatic cell genetic techniques: A comparison of relative map order derived by each method. Cytogenet. Cell Genet. 40: 655.

29. Kenwrick, S., PATtrerson, M., SPEer, A., FischbeCK, K., AND DAviES, K. (1987). Molecular analysis of the Duchenne muscular dystrophy region using pulsed field gel electrophoresis. Cell 48: 351-357.

30. KNUDSON, A. G., AND STRONG, L. C. (1972). Mutation and cancer: A model for Wilms' tumor of the kidney. J. Nath. Cancer Inst. 48: 313-324.

31. KORENBERG, J. R., AND RYKowSKI, M. C. (1988). Human genome organization: Alu, lines and the structure of metaphase chromosome bands. Cell 53: 391-400.

32. Koufos, A., Hansen, M. F., Lampkin, B. C., Workman, L. C., Copeland, N. G., Jenkins, N. A., AND CAVENEE, W. K. (1984). Loss of alleles at loci on human chromosome 11 during genesis of Wilms' tumor. Nature (London) 309: 170-172.

33. LEWIS, W. H., YEGER, H., BONETTA, L., CHAN, H. S. L., KANG, J., JUNEN, C., COWELL, J., JONES, C., AND DAFOE, L. A. (1988). Homozygous deletion of a DNA marker from chromosome 11p13 in sporadic Wilms tumor. Genomics 3: 25-31.

34. LINDSAY, S., AND BIRD, A. P. (1987). Use of restriction enzymes to detect potential gene sequences in mammalian DNA. Nature (London) 327: 336-338.

35. Moore, J. W., Hyman, S., Antonarakis, S. E., Mules, E. H., AND THOMAS, G. H. (1986). Familial isolated aniridia associated with a translocation involving chromosomes 11 and 22 [t(11;22)(p13;q12.2)]. Hum. Genet. 72: 297-302.

36. ORBaCh, M. J., Vollrath, D., Davis, R. W., AND Yanofsky, C. (1988). An electrophoretic karyotype of Neurospora crassa. Mol. Cell. Biol. 8: 1469-1473.

37. ORkin, S. H., Goldman, D. S., AND Sallan, S. E. (1984). Development of homozygosity for chromosome 11p markers in Wilms' tumor. Nature (London) 309: 172-174.

38. Porteous, D. J., Bickmore, W., Christe, S., Boyd, P. A., Cranston, G., Fletcher, J. M., Gosden, J. R., Rout, D., Seawright, A., Simola, K. O. J., van HeYningen, V., AND HASTIE, N. D. (1987). HRAS1-selected chromosome transfer generates markers that colocalize aniridia and genitourinary dysplasia-associated translocation breakpoints and the Wilms tumor gene within band 11p13. Proc. Natl. Acad. Sci. USA 84: 5355-5359.

39. Poustka, A., Lehrach, H., Williamson, R., and Bates, G. (1988). A long-range restriction map encompassing the cystic fibrosis locus and its closely linked genetic markers. Genomics 2: 337-345.

40. Reeve, A. E., HousiauX, P. J., Gardner, R. J. M., Chewings,
W. E., GRINDLEY, R. M., AND MrLLow, L. J. (1984). Lose of a Harvey ras allele in sporadic Wilms' tumor. Nature (London) 309: 174-176.

41. RicCardi, V. M., HitTNER, H. M., Francke, U., YUNis, J. J., LEDBETTER, D., AND BORGES, W. (1980). The aniridia-Wilms' tumor association: The critical role of chromosome band 11p13. Cancer Genet. Cytogenet. 2: 131 137.

42. Rogler, C. E., Sherman, M., SU, C. Y., Shafritz, D. A., SUMMERS, J., SHOWS, T. B., HENDERSON, A., AND KEW, M. (1985). Deletion in chromosome 11p associated with a hepatitis B integration site in hepatocellular carcinoma. Science 230: 319322.

43. RUSSELL, L. J., AND WeISSKOPF, B. (1986). Cognition in aniridia-Wilms tumor association: Analysis of karyotype associations. Amer. J. Hum. Genet. 39: A78.

44. SCHWARTZ, D. C., AND CANTOR, C. R. (1984), Separation of yeast chromosome-sized DNAs by pulsed field gradient gel electrophoresis. Cell 37: 67-75.

45. SHANNON, R. S., MANN, J. R., HARPER, E., HARNDEN, D. G., MORTEN, J. E. N., AND HERBERT, A. (1982). Wilms's tumor and aniridia: Clinical and cytogenetic features. Arch. Dis. Childhood 57: 685-690.

46. Simola, K. O. J., KNUUTila, S., Kattila, I., Pakola, A., AND POHJA, P. (1983). Familial aniridia and translocation $t(4 ; 11)(q 22 ; p 13)$ without Wilms' tumor. Hum. Genet. 63: 158161.

47. Smrth, C. L., Matsumoto, T., Niwa, O., Krco, S., Fan, J.-B., YanaGida, M., and CaNToR, C. R. (1987). An electrophoretic karyotype for Schizasaccharomyces pombe by pulsed field gel electrophoresis. Nucleic Acids Res. 15: 4481.

48. SOR, F. (1988). A computer program allows the separation of a wide range of chromosome sizes by pulsed field gel eloctrophoresis. Nucleic Acids Res. 16: 4853-4863.

49. Turleau, C., DE Grouchy, J., Tournade, M.-F., GagnadouX, M.-F., AND JUNIEN, C. (1984). Del 11p/aniridia complex: Report of three patients and review of 37 observations from the literature. Clin. Genet. 26: 356-362.

50. VAN OMMEN, G.-J. B., VERKERK, J. M. H., HOFKER, M. H., MONACO, A. P., KUNKEL, L. M., RAY, P., WORTON, R., WIERINGA, B., BAKKER, E., AND PEARSON, P. L. (1986). A physical map of 4 million bp around the Duchenne muscular dystrophy gene on the human X-chromosome. Cell 47: 499-504.

51. Vollrath, D., AND Davis, R. W. (1987). Resolution of DNA molecules greater than 5 megabases by contour-clamped homogeneous electric fields. Nucleic Acids Res. 15: 7865-7876.

52. WATKINS, P. C., EDDY, R., BECK, A. K., VELUCCI, V., LEVERONE, B., TANZI, R. E., GUSELlA, J. F., AND SHOWS, T. B. (1987). DNA sequence and regional assignment of the human folliclestimulating hormone beta subunit gene to the short arm of human chromosome 11. DNA 6: 205-212. 